\title{
ANALISIS MODEL MENTAL MAHASISWA PENDIDIKAN KIMIA DALAM MEMAHAMI JENIS REAKSI KIMIA
}

\section{ANALYSIS ON THE MENTAL MODEL OF UNDERGRADUATE STUDENT'S CHEMISTRY EDUCATION UNDERSTANDING THROUGH CHEMICAL REACTION TYPES}

\author{
Supriadi $^{1 *}$, Suhadi Ibnu ${ }^{2)}$, Yahmin ${ }^{2)}$ \\ ${ }^{1)}$ Program Studi Pendidikan Kimia, Fakultas Keguruan dan Ilmu Pendidikan, Universitas Mataram. Jalan Majapahit no \\ 62 Mataram, 83125, Indonesia \\ ${ }^{2)}$ Program Studi Pendidikan Kimia, Pascasarjana Universitas Negeri Malang. Jalan Semarang no 5 Malang, 65145, \\ Indonesia \\ *Email : supriadi_fkip@unram.ac.id
}

Diterima: 17 Januari 2018. Disetujui: 22 Februari 2018. Dipublikasikan: 31 Maret 2018

\begin{abstract}
Abstrak: Tujuan dari penelitian ini adalah untuk menggali model mental mahasiswa dalam memahami berbagai jenis reaksi kimia berdasarkan perbedaan pengetahuan awal. Sampel terdiri dari 152 mahasiswa yang berasal dari semester 1,3, dan 5 Program Studi Pendidikan Kimia, Universitas Mataram. Desain penelitian yang digunakan dalam penelitian ini adalah desain penelitian kualitatif deskriptif. Sebanyak 10 item soal tes essay dikembangkan tentang topik reaksi pembentukan, reaksi penguraian, reaksi pembakaran, reaksi substitusi tunggal dan reaksi substitusi ganda untuk mengidentifikasi model mental mahasiswa dan 19 soal tes pilihan ganda untuk mengidentifikasi pengetahuan awal mahasiswa. Hasil penelitian menunjukkan bahwa sebanyak 74,3 \% mahasiswa masih mengembangkan model mental inisial dalam menjelaskan fenomena reaksi pada level submikroskopik dan belum ada mahasiswa yang mengembangkan model mental saintifik. Mereka hanya menjelaskan proses terjadinya reaksi kimia pada level makroskopik dan simbolik. Selain itu dalam model mental mahasiswa, masih terdapat pra konsep yang dapat menyebabkan miskonsepsi. Peneliti menyarankan bahwa perlu diterapkan pembelajaran yang berbasis multi level representasi dan perlu dikembangkan media pembelajaran yang dapat meningkatkan model mental mahasiswa karena pengembangan model mental sangat penting dalam memahami konsep-konsep kimia.
\end{abstract}

Kata kunci: model mental, pengetahuan awal, reaksi kimia, representasi submikroskopik

\begin{abstract}
The objective of this study was to investigate students' mental models in understanding various types of reactions studied from different prior knowledge. The research design employed in this study was qualitative descriptive design. The sample consisted of 152 students from all students in $1^{\text {st }}, 3^{\text {rd }}$, and $5^{\text {th }}$ semester of Chemistry Education in Mataram University. There were ten essay tests about formation reactions, decomposition reaction, combustion reaction, single substitution reaction, and double substitution reaction employed to identify students' mental models, and 19 multiple choice items to identify students' prior knowledge. The results revealed that $74,3 \%$ of the students possess initial mental models in describing reactions in submicroscopic level and scientific models did not yet come up. Their descriptions about chemical reactions were just limited to macroscopic and symbolic level. Besides, there were preconcept found in students' mental models that caused misconceptions. Thus, the researchers suggest that it is important to conduct a lesson which is based on multi-level representation, and it is also important to develop a learning media that could improve students' mental models because the development of complete mental model is very important in understanding the concepts of chemistry.
\end{abstract}

Keywords: mental models, prior knowledge, chemical reactions, submicroscopic representation.

\section{PENDAHULUAN}

Materi pelajaran kimia seperti materi pelajaran ilmu pengetahuan alam yang lain mengandung konsepkonsep kompleks dan abstrak. Untuk mempelajari konsep yang kompleks dan abstrak tersebut dibutuhkan alat bantu pembelajaran yang bersifat nyata dan dapat dilihat untuk membantu pebelajar memahami konsep baru [1]. Untuk memahami konsep kimia, pebelajar harus memahami tiga level representasi. Menurut Johnstone [2] tiga level representasi kimia meliputi, level makroskopik, submikroskopik, dan simbolik. Dari ketiga level representasi tersebut, pebelajar sering kesulitan dalam memahami level submikroskopik karena bersifat abstrak (tidak dapat diobservasi). Pebelajar harus mengembangkan model mental ketika mempelajari konsep pada level submikroskopik $[1,3,4]$.

Menurut Coll [5] pengembangan model mental sangat penting dalam mempelajari kimia karena pengembangan teori dan praktik kimia dan sains diawali dengan pengembangan model mental. Bodner dan Domin [6] menyatakan bahwa pengembangan model mental diperlukan dalam memprediksi, menguji ide baru dan memecahkan masalah dalam pembelajaran kimia. Menurut Jansoon et al. [7] model mental digunakan untuk menjelaskan sistem dan komponen-komponen serta keadaannya, menjelaskan perilakunya ketika 
berubah dari satu keadaan ke keadaan lain dan untuk memprediksi keadaan sistem yang akan terjadi.

Menurut Laliyo [8] model mental menarik untuk diteliti karena model mental mempengaruhi fungsi kognitif dan dapat memberikan informasi yang berharga bagi para peneliti pendidikan sains tentang konsep yang dimiliki pebelajar. Namun, model mental sulit diidentifikasi, sukar dipahami, dan sulit dideskripsikan [9]. Model mental seseorang dapat diidentifikasi melalui interpretasi expressed mental model, yaitu model mental yang diekspresikan menggunakan lisan, tulisan dan gambar [9].

Model mental yang mungkin dikembangkan oleh pebelajar ada dua macam, yaitu model mental ilmiah dan model mental non-ilmiah. Halim dkk. [10] menyatakan bahwa model mental non-ilmiah adalah ide yang tidak sesuai dengan konsep ilmiah. Guru harus mengetahui bagaimana pebelajar mengembangkan model mental mereka untuk meyakinkan bahwa mereka tidak mengembangkan model mental yang salah (model mental non-ilmiah). Menurut Kurnaz \& Emen [11] model mental non-ilmiah disebabkan oleh pembelajaran yang tidak tepat dan kurangnya materi yang dipelajari. Pengembangan model mental non-ilmiah dalam pikiran pebelajar akan menyebabkan terjadinya miskonsepsi [12]. Lebih lanjut Vosniadou [13] menjelaskan bahwa model mental non ilmiah ada dua jenis, yaitu initial model dan synthetic model. Initial model adalah persepsi yang tidak sesuai dengan pengetahuan ilmiah sedangkan synthetic model adalah persepsi yang sebagian sesuai atau sebagian tidak sesuai dengan pengetahuan ilmiah.

Pengetahuan awal yang dimiliki pebelajar juga sangat mempengaruhi pengembangan model mental pebelajar [12]. Lajium [14] menjelaskan bahwa dalam proses belajar, pebelajar akan mengalami tahap asimilasi dan akomodasi. Pada tahap asimilasi, pebelajar akan menggunakan konsep-konsep yang telah dimiliki untuk menghadapi masalah baru. Pada tahap akomodasi, pebelajar mengubah konsep yang tidak cocok dengan masalah yang baru dihadapi. Konsep-konsep yang sudah ada dalam diri pebelajar merupakan pengetahuan awal. Pengetahuan awal berpengaruh dalam proses pengembangan model mental pebelajar sehingga perlu diperhatikan agar pebelajar mampu mengembangkan model mental ilmiah. Pengetahuan awal dalam hal ini adalah konsep-konsep yang telah dipelajari oleh pebelajar dan terkait dengan konsep-konsep yang ada pada materi reaksi kimia. Oleh karena itu perlu dilakukan identifikasi pengetahuan awal dan bagaimana dia menggunakan kemampuan tersebut dalam mengembangkan model mentalnya dalam menjelaskan suatu fenomena kimia.

Konsep reaksi kimia merupakan salah satu materi yang harus diajarkan oleh calon guru karena reaksi kimia merupakan dasar dalam mempelajari segala jenis fenomena kimia. Agar pebelajar sukses mengembangkan model mental ilmiah pada konsep ini, maka guru harus terlebih dahulu memiliki model mental yang utuh dan benar tentang konsep tersebut. Oleh karena itu perlu dilakukan identifikasi model mental calon guru kimia dalam memahami reaksi kimia, karena penelitian tentang identifikasi model mental pebelajar pada konsep reaksi kimia masih sangat sedikit. Sebagian besar fenomena di alam terjadi melalui reaksi kimia. Dengan memahami reaksi kimia secara mendalam, pebelajar akan mampu menjelaskan fenomena-fenomena alam yang terjadi dalam kehidupan sehari-hari. Dalam memahami reaksi kimia lebih lanjut, dibutuhkan pengetahuan awal yang berkaitan dengan reaksi kimia. Pebelajar harus sudah memahami konsep hukum kekekalan massa, termodinamika/termokimia, energi aktivasi, teori tumbukan, mekanisme reaksi, spontanitas dan reaksi redoks sebelum mempelajari berbagai jenis reaksi kimia [15].

Beberapa penelitian tentang model mental pebelajar telah dilakukan di Indonesia, seperti penelitian yang dilakukan oleh Fitriyani [16]. tentang model mental pebelajar dalam memahami materi termokimia. Namun, belum pernah dilakukan identifikasi model mental mahasiswa calon guru kimia dalam memahami berbagai jenis reaksi kimia termasuk calon guru di Universitas Mataram, NTB. Jika model mental mereka sudah diketahui, maka dapat dirancang pembelajaran yang dapat mencegah terjadinya miskonsepsi $[3,4,16]$. Untuk selanjutnya agar tidak terjadi miskonsepsi juga pada siswa yang akan diajar ketika mereka sudah menjadi guru.

Penelitian ini bertujuan untuk menggali dan mengevaluasi model mental mahasiswa dalam memahami proses terjadinya reaksi pembakaran hidrokarbon ditinjau dari pengetahuan awal yang berbeda. Penelitian ini mengidentifikasi bagaimana mahasiswa mendeskripsikan dan menggambar proses terjadinya reaksi pembakaran pada level makroskopik, simbolik dan submikroskopik.

\section{METODE PENELITIAN}

\section{Rumusan Masalah}

Penelitian ini menjawab rumusan masalah, yaitu (1) bagaimana jenis mental yang dikembangkan mahasiswa? (2) Bagaimana model mental mahasiswa yang memiliki pengetahuan awal rendah, sedang, dan tinggi tentang 5 jenis reaksi kimia? (3) Bagaimana kecendrungan model mental mahasiswa semester 1,3, dan 5 dalam memahami 5 jenis reaksi kimia? (4) Apa tingkatan model mental yang dikembangkan oleh mahasiswa?

\section{Desain Penelitian}

Desain penelitian yang digunakan dalam penelitian ini adalah penelitian deskriptif. Namun, data dikumpulkan secara kualitatif dan kuantitatif melalui kuesioner tertulis dan wawancara tidak terstruktur.

\section{Sampel Penelitian}

Sampel dalam penelitian ini adalah semua mahasiswa Program Studi Pendidikan Kimia Universitas 
Mataram yang berjumlah 152 mahasiswa, yaitu 66 mahasiswa semester 1, 42 Mahasiswa semester 3, dan 44 mahasiswa semester 5 .

\section{Instrumen Penelitian}

Dalam mengungkap model mental, harus dimulai dengan pertanyaan yang berkaitan dengan konsep. Dalam penelitian ini, mahasiswa diberikan 10 soal yang berkaitan dengan video tentang topik reaksi pembentukan, reaksi penguraian, reaksi pembakaran, reaksi substitusi tunggal dan reaksi substitusi ganda.

Selain itu, mahasiswa juga diminta untuk menjawab soal-soal tes identifikasi pengetahuan awal yang berisi 19 item soal yang mencakup konsep energi aktivasi, termokimia, laju reaksi, teori tumbukan, konsep kelarutan, spontanitas reaksi, dan mekanisme reaksi. Semua konsep tersebut diterapkan dalam menjelaskan proses terjadinya reaksi kimia. Semua soal, baik tes model mental maupun tes pengetahuan awal sudah dinyatakan valid oleh dua orang dosen pendidikan kimia Universitas Negeri Malang.

Selanjutnya model mental mahasiswa kemudian dihubungkan dengan tingkat pengetahuan awal yang dimilikinya. Selain itu, model mental mahasiswa juga dihubungkan dengan tingkatan semesternya.

Tabel 1. Rubrik Model Mental Mahasiswa

\begin{tabular}{l|l}
\hline $\begin{array}{c}\text { Jenis model } \\
\text { mental }\end{array}$ & \multicolumn{1}{c}{ Konten } \\
\hline $\begin{array}{l}\text { Model } \\
\text { inisial }\end{array}$ & $\begin{array}{l}\text { Persepsi yang tidak sesuai dengan } \\
\text { pengetahuan ilmiah: jawaban pada } \\
\text { level 0 (TM) atau 1 (GS) }\end{array}$ \\
\hline $\begin{array}{l}\text { Model } \\
\text { sintetik }\end{array}$ & $\begin{array}{l}\text { Persepsi yang sebagian sesuai atau } \\
\text { sebagian tidak sesuai dengan } \\
\text { pengetahuan ilmiah: jawaban pada } \\
\text { level 2 (GSB-GN) atau 3 (GSB) }\end{array}$ \\
\hline $\begin{array}{l}\text { Model } \\
\text { saintifik }\end{array}$ & $\begin{array}{l}\text { Persepsi yang sesuai dengan } \\
\text { pengetahuan ilmiah: jawaban pada } \\
\text { level 4 (GB) }\end{array}$ \\
\hline
\end{tabular}

Sumber: Kurnaz \& Eksi [17]

\section{HASIL DAN PEMBAHASAN}

\section{Jenis Model Mental Mahasiswa}

Berdasarkan hasil analisis terhadap seluruh penjelasan mahasiswa, diperoleh dua jenis model mental yang dimiliki mahasiswa, yaitu model inisial dan model sintetik, sedangkan model saintifik belum terlihat.

\section{a. Model Inisial}

Dalam model mental inisial, pemahaman mahasiswa hanya sampai pada level makroskopik dan simbolik, sedangkan level submikroskopik belum terlihat. Sebagai contoh pertanyaan tentang alasan mengapa suatu reaksi terjadi, mahasiswa yang memiliki model mental inisial hanya menjelaskan secara makroskopik bahwa reaksi terjadi tanpa melalui mekanisme reaksi dan tanpa melibatkan energi maupun tumbukan. Hasil visuaisasi mahasiswa juga masih pada tingkat makroskopik dan simbolik. Mahasiswa menggambarkan bentuk wadah dari reaktan, tetapi tidak menggambarkan bentuk molekul dari reaktan tersebut.

Pada model mental inisial, mahasiswa memiliki beberapa pra-konsep dalam menjelaskan proses terjadinya reaksi kimia. Semua pra-konsep tersebut merupakan miskonsepsi yang dimiliki mahasiswa. Model mental tersebut yaitu: (1) percikan api merupakan katalis yang mempercepat terjadinya reaksi pembakaran, (2) setetes air berfungsi untuk mengubah fase logam natrium, (3) setetes air berfungsi sebagai katalisator untuk mempercepat terjadinya reaksi pembentukan $\mathrm{NaCl}$, (4) pengendapan terjadi karena zat terlarut bersifat non-polar, dan (5) larutan $\mathrm{HCl}$ dapat melarutkan logam $\mathrm{Zn}$ karena larutan $\mathrm{HCl}$ merupakan asam kuat dan bersifat elektrolit kuat.

\section{Model Sintetik}

Dalam model mental sintetik, pemahaman mahasiswa tentang proses terjadinya berbagai jenis reaksi kimia sudah sampai pada level submikroskopik. Mahasiswa sudah mampu menjelaskan aspek energi yang menyertai reaksi. Namun, mahasiswa belum mampu menghubungkan antar level representasi. Model mental sintetik yang dikembangkan mahasiswa, yaitu: (1) massa kristal pada reaksi penguraian berkurang karena ada sejumlah gas yang lepas dari kristal, (2) percikan api atau pemanasan pada reaksi pembakaran berfungsi untuk meningkatkan jumlah tumbukan antara hidrokarbon dan gas oksigen, (3) percikan api atau pemanasan pada reaksi pembakaran berfungsi untuk melampaui energi aktivasi, (4) reaksi antara logam $\mathrm{Zn}$ dengan asam dapat terjadi secara spontan karena logam $\mathrm{Zn}$ berada di sebelah kiri atom $\mathrm{H}$ pada deret volta, dan (4) pengendapan terjadi karena zat terlarut memiliki nilai Ksp yang lebih kecil dibandingkan dengan nilai Qc-nya.

\section{Hubungan Model Mental dengan Tingkat Pengetahuan Awal}

Semua kategori pengetahuan awa mengembangkan model mental yang sama, yaitu model mental inisisal dan sintetik. Berdasarkan Tabel 4.1 terlihat bahwa mahasiswa yang memiliki model mental inisial lebih banyak dibandingkan dengan mahasiswa yang memiliki model mental sintetik pada setiap tingkatan pengetahuan awal. Namun, terjadi peningkatan persentase mahasiswa yang memiliki model mental sintetik dari pengetahuan awal rendah ke tinggi. Selain itu, terjadi penurunan persentase mahasiswa yang memiliki model mental inisial dari pengetahuan awal rendah ke tinggi. Hal ini menunjukkan bahwa semakin tinggi pengetahuan awal mahasiswa, maka model mental yang dikembangkan semakin mendekati model mental saintifik. Berikut ditampilkan hubungan model mental mahasiswa dengan pengetahuan awal (Gambar 4). 


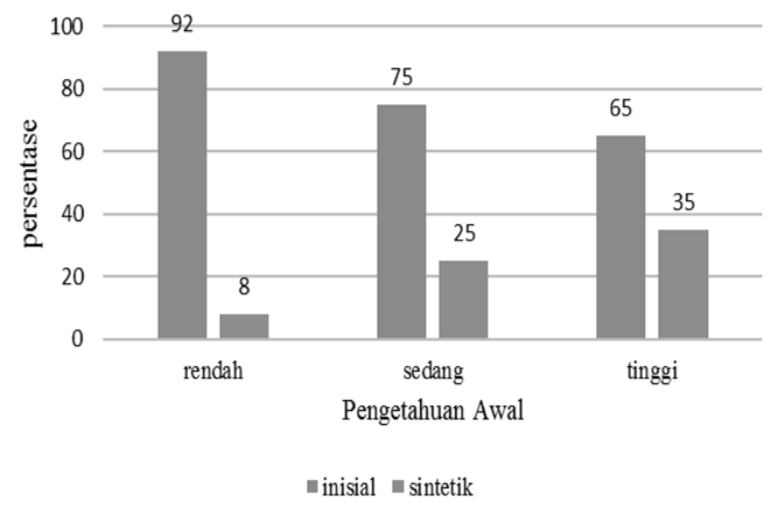

Gambar 4 Grafik Hubungan Model Mental dengan Pengetahuan Awal

Mahasiswa yang memiliki pengetahuan awal rendah sebagian besar mengembangkan model mental inisial. Model mental inisial yang mereka kembangkan masih banyak terdapat prakonsep non ilmiah yang dapat menyebabkan miskonsepsi. Penjelasan mereka hanya pada level makroskopik dan tidak menghubungkan proses terjadinya reaksi kimia dengan aspek energi dan mekanisme reaksi.

Selain model mental inisial, sebagian kecil mahasiswa yang memiliki pengetahuan awal rendah juga mengembangkan model mental sintetik.

Sebagaian besar mahasiswa yang memiliki pengetahuan awal sedang juga mengembangkan model mental inisial. Namun jumlahnya lebih sedikit dibandingkan mahasiswa berpengetahuan awal rendah. Model mental yang mereka kembangkan juga masih pada level makroskopik, sama seperti mahasiswa berpengetahuan awal rendah.

Mahasiswa yang memiliki pengetahuan awal tinggi juga mengembangkan model mental inisial, tetapi lebih sedikit dibandingkan mahasiswa yang berpengetahuan awal sedang dan rendah.

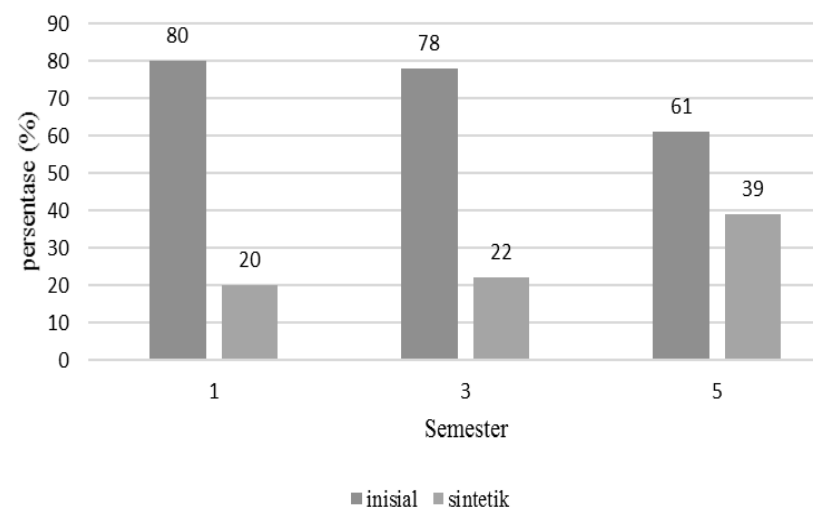

Gambar 5 Hubungan Model Mental dengan

Tingkat Angkatan

\section{Hubungan Model Mental dengan Pengalaman Belajar \\ Hasil penelitian menunjukkan bahwa sebagian besar mahasiswa pada tiap angkatan juga}

mengembangkan model mental inisial. Hal ini disebabkan karena pada setiap angkatan jarang diberikan pembelajaran yang dapat meningkatkan kemampuan mahasiswa dalam memvisualisasikan reaksi kimia pada level partikulat. Berikut ditampilkan grafik hubungan model mental mahasiswa dengan tingkat angkatannya.

Berdasarkan Gambar 5 persentase jenis model mental antara semester 1 dan semester 3 tidak berbeda secara signifikan. Hal ini terjadi karena berdasarkan pengalaman peneliti, pembelajaran kimia yang didapatkan pada semester 1 dan 3 tidak berbeda, yang berbeda adalah mata kuliah ilmu pendidikan. Mata kuliah kimia yang didapatkan pada semester 3 sebagian besar mengulang mata kuliah kimia dasar pada semester 1 sehingga pemahaman konsep yang didapatkan tidak berbeda. Berbeda dengan semester 5, di mana materi kimia yang didapatkan sudah mendalam dan terdapat mata kuliah pilihan yang merupakan mata kuliah terapan. Oleh karena itulah terjadi perbedaan persentase yang signifikan antara semester 3 dengan semester 5 .

Dari hasil ini, diusulkan bahwa model mental mahasiswa harus dipertimbangkan dalam proses perancangan dan penerapan proses pembelajaran. Dalam arti ini, diusulkan untuk menggunakan metode pelatihan dan teknik yang akan mengembangkan terutama kemampuan spasial mahasiswa dalam perkuliahan [9].

\section{KESIMPULAN}

Berdasarkan hasil dan pembahasan, maka dapat disimpulkan bahwa: (1) model mental yang dikembangkan mahasiswa ada dua jenis, yaitu model mental inisial dan model mental sintetik, (2) sebagian besar mahasiswa mengembangkan model mental inisial dan tidak ada mahasiswa yang mengembangkan model mental saintifik, (3) semakin tinggi tingkat pengetahuan awal, persentase mahasiswa yang memiliki model mental inisial semakin menurun sedangkan persentase mahasiswa yang memiliki model mental sintetik semakin meningkat, (4) semakin tinggi tingkat semester mahasiswa, persentase mahasiswa yang memiliki model mental inisial semakin menurun sedangkan persentase mahasiswa yang memiliki model mental sintetik semakin meningkat.

\section{SARAN}

Peneliti menyarankan bahwa perlu diterapkan pembelajaran yang berbasis multilevel representasi dan perlu dikembangkan media pembelajaran yang dapat meningkatkan model mental mahasiswa karena pengembangan model mental saintifik sangat penting dalam memahami konsep-konsep kimia.

\section{DAFTAR PUSTAKA}

[1] Chittleborough, G. D., Treagust, D. F., \& Mocerino, M. 2002. Constraints to development of first year university chemistry students' mental models of 
chemical phenomena. Teaching and Learning Forum. Focusing on Student.

[2] Johnstone, A. H. (1982). Macro - and micro chemistry. School Science Review, 64: 377-379.

[3] Siahaan, J., \& Sukib, S. (2017). Media Demonstrasi Kimia Yang Dimodifikasi Untuk Mengatasi Miskonsepsi Mahasiswa Pada Topik Sel Elektrokimia. Jurnal Pijar MIPA, 12(1).

[4] Aprianti, R., Wildan, W., \& Muntari, M. (2011). Pengembangan Modul Pembelajaran Larutan Asam Basa Berbasis Pendekatan Mms (Makroskopik Mikroskopik Simbolik) Dan Implementasinya Dalam Pembelajaran. Jurnal Pijar MIPA, 6(1).

[5] Coll, R. K. 2008.Chemistry Learners' Preferred Mental Models for Chemical Bonding. Journal of Turkish science Education; 5(1): 22-47.

[6] Bodner, G. M \& Domin, S. D. 2000. Mental Models: The Role of Representations in Problem Solving in Chemistry. University of Education, 4 (1): 24-30.

[7] Jansoon, N., Coll, R. K., \& Somsook, E. 2009. Understanding Mental Model of Dilution in Thai Students.

[8] Laliyo, L. A. R. 2011. Model Mental Siswa Dalam Memahami Perubahan Wujud Zat. Jurnal Penelitian dan Pendidikan, 8 (1): 1-12.

[9] Coll R. K. \& Treagust, D. F. 2003. Investigation of Secondary School, Undergraduate, and Graduate Learners' Mental Models of Ionic Bonding. Journal of Research in Science Teaching, 40 (5): 464-486.

[10] Halim, N. D. A, Ali, M. B., Yahaya, N., Said, \& M. N. H. M. 2013. Mental Model in Learning Chemical Bonding: A Preliminary Study. The 9th International Conference on Cognitive Science.

[11] Kurnaz, M. A., \& Emen, A. Y. 2013. Mental Models of the High School Students Related To the Contraction of Matter. International Journal of Educational Research and Technology, 4(1): 1-5.

[12] Krause, S., Kelly, J., Corkins J., \& Tasooji A. 2009. Using Students' Previous Experience and Prior Knowledge to Facilitate Conceptual Change in an Introductory Materials Course. 39th ASEE/IEEE Frontiers in Education Conference.

[13] Vosniadou, S., \& Brewer, W. F. (1992). Mental models of the earth: a study of conceptual change in childhood. Cognitive Psychology, 24: 535-585.
[14] Lajium, D. A. D. 2013. Students' Mental Models of Chemical Reactions. Disertasi yang tidak dipublikasikan.

[15] Wade, L. G. (2013). Organic chemistry (8th ed.). Boston, MA: Pearson

[16] Lin, J. W., Chiu, M. H., \& Liang, J. C. 2004. Exploring mental models and causes of students' misconceptions in acids and bases. Paper presented at the NARST, Vancouver, Canada.

[17] Kurnaz, M. A. \& Eksi, C. 2015. An Analysis of High School Students' Mental Models of Solid Friction in Physics. Educational Sciences: Theory \& Practice, 15(3): 787-795. 